\title{
Bacteriological aspects of chronic osteoarticular infections in adults: the influence of the osteosynthesis material
}

\author{
Adil Maleb ${ }^{1,2^{*}} \mathbb{D}$, Mohammed Frikh ${ }^{1,2}$, Yassine Ben Lahlou ${ }^{1,2}$, Belkacem Chagar ${ }^{3}$, \\ Abdelhay Lemnouer ${ }^{1,2}$ and Mostafa Elouennass ${ }^{1,2}$
}

\begin{abstract}
Background: The aim of this study is to establish the bacterial epidemiology of chronic osteoarticular infections in adults, to study the susceptibility of the isolated strains to antibiotics and to demonstrate the influence of osteosynthesis material thereon.

Patients and methods: This is a retrospective study of 78 months, from January 2006 to June 2012, providing bacteriological samples from patients with osteitis and osteoarthritis in the Mohammed $V$ military teaching hospital of Rabat. Isolation and identification of bacteria were made by bacteriological classical techniques. The antimicrobial susceptibility testing of the isolates was performed by disk diffusion agar method, as recommended by the Committee of the susceptibility of the French Society for Microbiology (CA-SFM).

Results: We collected 234 cases, 53\% ( $n=124)$ of patients without osteosynthesis material (group A) and 47\% $(n=110)$ patients with osteosynthesis material (group B).We isolated 371 bacteria which $51.49(n=191)$ in group $A$ and $48.51 \%(n=180)$ in group B. Gram-positive cocci were the most frequent $(n=234)$, followed by the Gram-negative bacilli $(n=114)$ and the Gram-positive bacilli $(n=19)$. Our study shows that the rate of resistance to antibiotics in strains obtained from patients with osteosynthesis material is higher compared to those obtained from patients without osteosynthesis material.
\end{abstract}

Conclusions: Chronic OA infection in adults is difficult to diagnose and treat. Its good management must be multidisciplinary.

Keywords: Antibiotic resistance, Bacteria, Infectious diseases, Orthopedic surgery

\section{Background}

The support of osteoarticular (OA) infections is often a difficult challenge. Usually chronic forms are not life threatening. However, they expose patients to serious disabling situations such as prolonged hospitalization, high total disability and inability up to 1 year. Furthermore, osteoarticular infections are a major therapeutic problem due to the selection of resistant mutants [1-3].

\footnotetext{
*Correspondence: maleb.adil@gmail.com

${ }^{1}$ Bacteriology Department, Mohammed V Military Teaching Hospital,

Rabat, Morocco

Full list of author information is available at the end of the article
}

The empirical antibiotic therapy has no place in OA infections, except in some emergency cases [4]. The optimal treatment of these infections; with or without osteosynthesis material (metal implants), passes first by a bacteriological documentation and a study of the sensitivity of the relevant bacteria to antibiotics [5].

The aim of this study is to establish the bacterial epidemiology of chronic osteoarticular infections in adults, to study the susceptibility of the isolated strains to antibiotics and to demonstrate the influence of osteosynthesis material thereon. 


\section{Patients and methods}

This is a retrospective study of 78 months, from January 2006 to June 2012, providing bacteriological samples from patients with osteitis and osteoarthritis in the Mohammed V military teaching hospital of Rabat. Bacteriological samples were distributed into two groups, group A: patients without osteosynthesis material and group B: patients with osteosynthesis material (rods, plates and screws). They were obtained by aspiration of the adjacent liquid of osteitis site during surgical exploration, by sampling tissue, or bone fragments, deep trimming product during surgery, or aspiration of joint fluid. Removed osteosynthesis material were sonicated, and solid samples were crushed in order to destroy the adherent biofilm and detach the bacteria to facilitate culture. All samples were inoculated under a microbiological safety cabinet type II, by a technician wearing sterile gloves to avoid contamination. Whether liquid or solid, all samples were inoculated onto rich media usually used in the laboratory: blood agar incubated in aerobic and anaerobic conditions at $37{ }^{\circ} \mathrm{C}$, chocolate agar supplemented with multivitamins in $5 \%$ of $\mathrm{CO} 2$ at $37^{\circ} \mathrm{C}$, traditional aerobic and anaerobic blood culture broths. Incubation of culture media were prolonged (at least 7 days) to allow the growth of fastidious bacteria, slow growing. Cultures under aerobic and $\mathrm{CO} 2$ were observed daily, anaerobic cultures every $48 \mathrm{~h}$, the enrichment broths were transplanted as soon as a disorder or a culture is observed; they were systematically replanted after at least 7 days of incubation on agar culture media and incubated again additional $48 \mathrm{~h}$. Culture of Mycobacteria was not routinely performed except if the clinician specifically requests it. Identification of bacteria were made by bacteriological classical techniques. The antimicrobial susceptibility testing of the isolates was performed by disk diffusion agar method, as recommended by the Committee of the susceptibility of the French Society for Microbiology (CA-SFM) [6]. Carbapenemases were sought by the test of Hodge (TH) in accordance with the same previous recommendations. The duplicates were collected only once and the bacteria belonging to the commensal flora (Coagulase negative Staphylococci, Corynebacterium spp., etc.) have been retained only when the same antibiotype was isolated many times.

\section{Results}

During this period of study we collected 234 samples (Table 1) originating from 234 different patients, 53\% $(n=124)$ of group A and $47 \%$ of group B $(n=110)$. In each case we isolated at least one bacterium. The Table 2 shows that culture permitted to isolate 371 bacteria which $51.49(\mathrm{n}=191)$ in group A and $48.51 \%(\mathrm{n}=180)$ in group B. Among isolates, Gram-positive cocci were the
Table 1 Distribution of specimens type $(n=234)$

\begin{tabular}{lcll}
\hline & Group A $(\mathbf{n = 1 2 4 )}$ & Group B $(\mathbf{n = 1 1 0})$ & $\begin{array}{l}\text { Group A + B } \\
(\mathbf{n = 2 3 4 )}\end{array}$ \\
\hline Deep pus & 46 & 50 & 96 \\
Bone & 53 & 33 & 86 \\
Joint fluid & 7 & 11 & 18 \\
Soft tissue & 8 & 5 & 13 \\
Fistulaswab & 10 & 2 & 12 \\
Material & 0 & 9 & 9 \\
\hline
\end{tabular}

most frequent $(\mathrm{n}=234)$, followed by the Gram-negative bacilli $(\mathrm{n}=114)$ and the Gram-positive bacilli $(\mathrm{n}=19)$. Among only 34 specific types of research of mycobacteria, we isolated four strains of Mycobacterium tuberculosis, all in group A. The difference was in the distribution of species between these two groups. With some exceptions, we found that the cocci predominated in group A and bacilli predominated in group B (Table 2).

The Staphylococci resistance rates of group A and group B are shown in Fig. 1. The rate of resistance of streptococci to penicillin $\mathrm{G}$ was $19.5 \%(\mathrm{n}=4)$ in group A and $37.5 \%(n=3)$ in group B. The Enterococci resistance rates to ampicillin were none in group A and $15.38 \%$ $(\mathrm{n}=2)$ in group B. The resistance rates of Streptococci and Enterococci to rifampicin was $5.56 \%(\mathrm{n}=2)$ in group A and $4.76 \%(\mathrm{n}=1)$ in group B.

Regarding the Enterobacteriaceae, the percentage of strains producing extended spectrum beta-lactamases with was $13.79 \%(\mathrm{n}=4)$ in group A and $42.86 \%(\mathrm{n}=18)$ in group B. One strain was producing carbapenemase, it belonged to group B. The overall rate of Gram-negative bacilli resistance to ciprofloxacin was $18.6 \%(\mathrm{n}=16)$ in group $A$ and $42.65 \%(n=29)$ in group $B$.

\section{Discussion}

In our series, we acknowledge that the study was only descriptive and no statistical analyses were performed and that many of the $\mathrm{n}=$ numbers for microorganism species were too small to analyse with confidence.

Gram-positive cocci were isolated in approximately two-thirds of patients $(\mathrm{n}=234 ; 63.07 \%)$ and Gram-negative bacilli in less than one in three $(\mathrm{n}=114 ; 30.72 \%)$ [In the distribution of the isolates of the total number of collected cases $(\mathrm{A}+\mathrm{B})]$. The remaining isolates were represented by Gram-positive bacilli $(\mathrm{n}=19)$ and Mycobacteria. Our series shows, as for other studies, that $S$. aureus ( $\mathrm{n}=85,22.90 \%$ ) was the most frequent causative agent regardless of the osteitis's type [1]. Staphylococci together accounted for only $46.63 \%(n=173)$ of all isolates. Their role in bone infections is related to their presence at the cutaneous and mucosal level, their adaptation 
Table 2 Distribution of isolates by groups and species $(\mathrm{n}=\mathbf{3 7 1})$

\begin{tabular}{|c|c|c|}
\hline & Group A & Group B \\
\hline & $\begin{array}{l}\text { Patients with- } \\
\text { out osteosyn- } \\
\text { thesis mate- } \\
\text { rial }(n=191)\end{array}$ & $\begin{array}{l}\text { Patients } \\
\text { with osteosyn- } \\
\text { thesis material } \\
(n=180)\end{array}$ \\
\hline \multicolumn{3}{|l|}{ Gram-positive cocci } \\
\hline \multicolumn{3}{|l|}{ Staphylococci } \\
\hline Coagulase-negative Staphylococci & 41 & 47 \\
\hline Staphylococcus aureus & 53 & 32 \\
\hline \multicolumn{3}{|l|}{ Streptococci } \\
\hline Streptococcus spp. & 14 & 5 \\
\hline$\beta$-hemolytic streptococci & 7 & 3 \\
\hline \multicolumn{3}{|l|}{ Enterococci } \\
\hline Enterococcus faecalis & 14 & 9 \\
\hline Enterococcus faecium & 1 & 4 \\
\hline \multicolumn{3}{|l|}{ Others } \\
\hline Micrococcus spp. & 0 & 2 \\
\hline Leuconostoc spp. & 2 & 0 \\
\hline \multicolumn{3}{|l|}{ Gram-negative bacilli } \\
\hline \multicolumn{3}{|l|}{ Enterobacteriaceae } \\
\hline Klebsiella pneumoniae & 6 & 12 \\
\hline Enterobacter cloacae & 6 & 12 \\
\hline Escherichia coli & 8 & 7 \\
\hline Proteus mirabilis & 2 & 5 \\
\hline Klebsiella oxytoca & 0 & 3 \\
\hline Morganella morganii & 2 & 1 \\
\hline Citrobacter koseri & 2 & 0 \\
\hline Citrobacter freundii & 1 & 1 \\
\hline Salmonella typhimurium & 2 & 0 \\
\hline Proteus vulgaris & 0 & 1 \\
\hline \multicolumn{3}{|l|}{ Non-fermenting bacteria } \\
\hline Pseudomonas aeruginosa & 11 & 12 \\
\hline Acinetobacter baumannii & 5 & 4 \\
\hline Pseudomonas mendocina & 0 & 2 \\
\hline Ochrobactrum anthropi & 0 & 2 \\
\hline Ralstonia pickettii & 0 & 1 \\
\hline Burkholderia cepacia & 0 & 1 \\
\hline \multicolumn{3}{|l|}{ Others } \\
\hline Aeromonas hydrophila & 1 & 4 \\
\hline \multicolumn{3}{|l|}{ Gram-positive bacilli } \\
\hline Corynebacterium spp. & 7 & 9 \\
\hline Bacillus spp. & 1 & 0 \\
\hline Listeria monocytogenes & 0 & 1 \\
\hline Actinomyces spp. & 1 & 0 \\
\hline \multicolumn{3}{|l|}{ Acid-fast bacilli (of 34 requests) } \\
\hline Mycobacterium tuberculosis & 4 & 0 \\
\hline
\end{tabular}

to infection of the bone (they adhere easily to the bone, cartilage, and surgical implants) [1, 7]. Streptococci and Enterococci were poorly isolated in our series. This would be partly due to the fact that they are frequently found during early infection. Indeed, they are rarely identified in chronic OA infections, due to their good response to antibiotics [8].

The Gram-negative bacilli were mainly represented by K. pneumoniae, E. cloacae, E. coli, and P. mirabilis in the group of Enterobacteriaceae and P. aeruginosa and $A$. baumannii in the non-fermenting Gram-negative bacilli group. These bacteria are more closely related to a nosocomial superinfection of the implanted osteosynthesis material, in some cases and for some species they may be secondary to post-traumatic osteitis [1, 8]. Gram-positive bacilli were dominated in our series by Corynebacteria. This group was generally considered contaminants but is currently increasing and described as the one responsible for osteitis. These species, such as coagulase-negative Staphylococci, originate from the skin or the environment and often dominate in intraoperative infections. They present problems of interpretation; the responsibility can be accepted only on deep samples. In these cases, isolation of the same organism in at least two locations or two samples is very comforting, justifying the increase in sampling sites [6].

In our series, the distribution of isolates between the two groups A and B shows that the cocci predominated in group $\mathrm{A}$, while bacilli predominated in group $\mathrm{B}$. The distribution by species shows that some bacteria derogate the distribution by groups. These include a predominance of E. coli, M. morganii, Citrobacter spp., S. typhimurium, and $A$. baumannii in group A and a slight predominance of coagulase-negative staphylococcal species in group B. The isolation of Enterobacteriaceae and A. baumannii in group A in our series would be linked to their community origin, despite their multiple resistances to antibiotics which is often seen in nosocomial strains [9-11].

The results of our study show that the rate of resistance to antibiotics in strains obtained from patients with osteosynthesis material are higher compared to those obtained from patients without osteosynthesis material. This is usually about multiresistant bacteria. Especially: Methicillin-resistant Staphylococcus aureus (MRSA), Streptococci resistant to penicillin G, Enterococciresistant to ampicillin, Enterobacteriaceae producing extended spectrum beta-lactamases (ESBLs), Enterobacteriaceae producing carbapenemase and Gram-negative bacilli resistant to ciprofloxacin.

Antibiotic resistance is an additional difficulty that complicates the therapeutic treatment of $\mathrm{OA}$ infections on the osteosynthesis material. This resistance is acquired by the bacteria before and/or after contamination of the patient subject to OA infection. Before contamination, the nature of nosocomial OA infections explains very clearly the transmission of multiresistant 


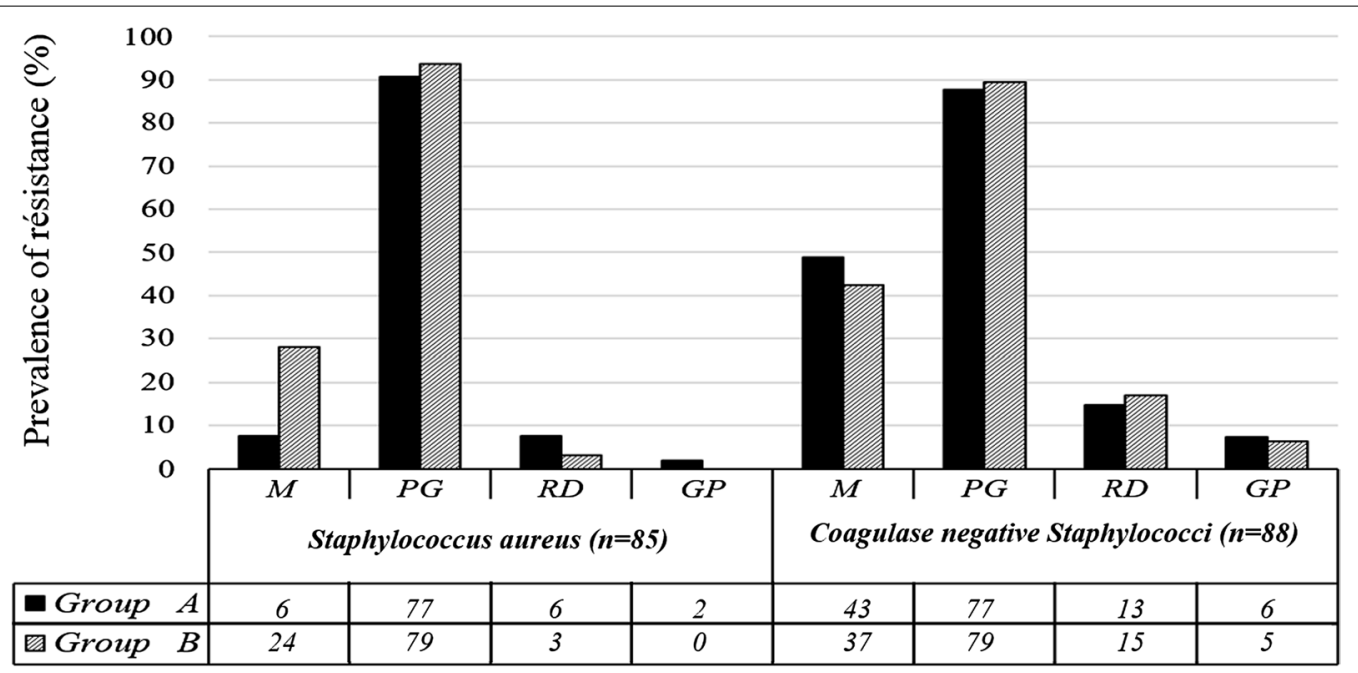

Fig. 1 Level of resistance of isolated Staphylococci. M methicillin, $P G$ penicillin G, RD rifampicin, GP glycopeptides

bacteria immediately among patients. After contamination, a multitude of factors contributes to the resistant mutant selection $[1,12,13]$ :

- Unreflective use of antibiotics.

- High efficiency of bone antibiotics are also more involved in bacterial resistance selection (rifampicin, fosfomycin, fluoroquinolones, clindamycin, fusidic acid).

- Deep localization of the OA infection significantly limits the spread of antibiotics.

- Osteosynthesis material causes the formation of biofilm, with all the consequences: limiting the spread of antibiotics, loss of sensitivity to certain antibiotics, prolonged persistence in osteoblasts, escape the immune defense mechanism.

\section{Conclusion}

Chronic OA infection in adults is difficult to diagnose and treat. Patients who have had orthopedic implants, when they become infected, are more likely to be infected with bacteria more virulent, more resistant to antibiotics, and better escape the immune system.

\section{Authors' contributions}

All authors have made substantial contributions to conception, to design, to acquisition of data, to analysis and to interpretation of data; All authors have been involved in drafting the manuscript or revising it critically for important intellectual content; All authors have given final approval of the version to be published. Each author have participated sufficiently in the work to take public responsibility for appropriate portions of the content. All authors have agreed to be accountable for all aspects of the work in ensuring that questions related to the accuracy or integrity of any part of the work are appropriately investigated and resolved. All authors read and approved the final manuscript.

\section{Author details}

${ }^{1}$ Bacteriology Department, Mohammed V Military Teaching Hospital, Rabat, Morocco. ${ }^{2}$ Research Team: Bacterial Epidemiology and Resistance, Mohammed V University, Faculty of Medicine and Pharmacy, Rabat, Morocco. ${ }^{3}$ Traumalogy Department, Mohammed V Military Teaching Hospital, Rabat, Morocco.

\section{Acknowledgements}

Not applicable.

\section{Competing interests}

The authors declares that they have no competing interests.

\section{Availability of data and materials}

The datasets used and/or analysed during the current study are available from the corresponding author on reasonable request.

\section{Consent to publish}

Not applicable.

\section{Ethics approval and consent to participate}

This study have been performed in accordance with the Declaration of Helsinki and have been approved by the ethics committee of Mohammed V Military Teaching Hospital of Rabat.

Informed consent to participate in this study have been obtained from participants (or their parent or legal guardian in the case of children under 16).

\section{Funding}

Not applicable.

\section{Publisher's Note}

Springer Nature remains neutral with regard to jurisdictional claims in published maps and institutional affiliations.

Received: 22 June 2016 Accepted: 22 November 2017

Published online: 28 November 2017

\section{References}

1. Elouennass $M$, et al. Les aspects bactériologiques des ostéites dans un hôpital universitaire. Med Mal Infect. 2007;37(12):802-8. 
2. Syrogiannopoulos GA, Nelson JD. Duration of antimicrobialtherapy for acute suppurative osteoarticular infections. Lancet. 1988;331(8575):37-40.

3. Roger PM, et al. Examens paracliniques et durée de l'antibiothérapie des infections ostéoarticulaires. Med Mal Infect. 2011;41(5):242-7.

4. Uckay l, et al. Prevention of surgical site infections in orthopaedic surgery and bone trauma: state-of-the-art update. J Hosp Infect. 2013:84(1):5-12.

5. Darouiche RO. Treatment of infections associated with surgical implants. N Engl J Med. 2004;350(14):1422-9.

6. Bonnet $\mathrm{R}$, et al. Comité de l'Antibiogramme de la Société Française de Microbiologie. Recommandations; 2013.

7. Peel TN, et al. Outcome of debridement and retention in prosthetic joint infections by methicillin-resistant staphylococci, with special reference to rifampin and fusidic acid combination therapy. Antimicrob Agents Chemother. 2013;57(1):350-5.

8. Tschopp O, Carmona G, Hoffmeyer P. Ostéosynthèse des membres et infection. Médecine et Hygiène. 2000;58(2322):2268-73.
9. Campillo B, Dupeyron C, Richardet JP. Epidemiology of hospital-acquired infections in cirrhotic patients: effect of carriage of methicillin-resistant Staphylococcus aureus and influence of previous antibiotic therapy and norfloxacinprophylaxis. Epidemiol Infect. 2001;127(03):443-50.

10. Tani ZBAK, Arlet G. Actualité de la résistance aux antibiotiques chez les bacilles à Gram négatif en Algérie. Pathol Biol (Paris). 2014;62(3):169-78.

11. Eveillard M, Joly-Guillou ML. Infections émergentes à Acinetobacter baumannii et circonstances favorisant leur survenue. Pathol Biol. 2012;60(5):314-9.

12. Ader $F$, et al. Origine de l'infection osseuse: endogène ou exogène? Éléments de physiopathologie. Med Mal Infect. 2004;34(11):530-7.

13. Groupe de Pathologie Infectieuse. Recommandations de pratique clinique Infections ostéo-articulaires sur matériel (prothèse, implant, ostéo-synthèse). Med Mal Infect. 2009;39:745-74.

\section{Submit your next manuscript to BioMed Central and we will help you at every step:}

- We accept pre-submission inquiries

- Our selector tool helps you to find the most relevant journal

- We provide round the clock customer support

- Convenient online submission

- Thorough peer review

- Inclusion in PubMed and all major indexing services

- Maximum visibility for your research

Submit your manuscript at www.biomedcentral com/submit 